\title{
The Indian Science Congress at Bombay.
}

UNDER the presidency of Mr. A. Howard, Director of the Institute of Plant Industry, Indore, and Agricultural Adviser to States in Central India, the thirteenth annual meeting of the Indian Science Congress was held at Bombay on January 4-9. In addition to sectional meetings, joint discussions were held on recent scientific work directed to the improvement of cotton-growing (Sections of Agriculture, Mathematics and Physics, Zoology and Botany) and on the structure of the atom and quantum theory (Sections of Mathematics and Physics and Chemistry). Public lectures on droughts and famines, by Dr. H. H. Mann, on life at higher altitudes in Western Tibet, by Prof. Shiv Ram Kashyap, and on modern applications of X-rays, by Prof. H. Parameshwaran, were arranged, as well as visits to places of scientific interest in the neighbourhood of Bombay.

Brief accounts indicating the activities of some of the sections of the Congress are printed below.

In his presidential address, Mr. A. Howard, after dwelling on the predominance in modern scientific agriculture of the biological sciences, went on to stress the diversity of the sciences with which modern research in agriculture is concerned. The study of the growth of the economic plant, according to Mr. Howard, opens up the great problem of the agriculture of the near future, and that is the intensive cultivation of improved varieties; it is not sufficient to breed new varieties : the methods by which maximum production can be obtained must be studied. From his general argument, Mr. Howard developed the thesis that the need of the future is team work. The real subjects of research in agriculture have far outgrown the old tradition inspired by the work of Liebig: the attack through a single science is no longer possible. It is rightly pointed out, however, that successful team work presupposes the presence of a competent leader and, it may be added, a spirit of subordination to which men with the real pioneering aptitudes do not readily submit.

An unusual and suggestive feature of Mr. Howard's address was the special reference to the connexion between canal irrigation and public health. $\mathrm{He}$ thinks that no satisfactory explanation has yet been given of the correlation between canal irrigation and the prevalence of malaria. He pointed out that the connexion cannot be wholly due to the formation by canals of breeding grounds for mosquitoes, and suggested that a contributory cause may be nutritional - the deficiency in the food crops grown with canal water of essential mineral and other ingredients. He urged the need for immediate investigation and deplored the cessation, for financial reasons, of the work of McCarrison (Jour. Roy. Soc. of Arts, 83, r925,

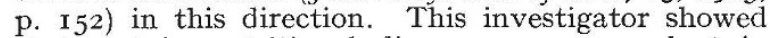
that certain nutritional diseases were prevalent in Madras as the result of differences in the manurial treatment of the millet crop.

In relation to the diseases of plants, also, $\mathrm{Mr}$. Howard broke fresh ground with a suggestion that cultural conditions rather than specific infection play the most important part in the causation of outbreaks. In some of his work at Quetta in connexion with fruit growing, he was able to show that attacks of aphis could be induced experimentally by altering the time of irrigation. $\mathrm{He}$ found, again, that Eincorn ( $T r$. monococeum), which is generally believed to be immune to Puccinia graminis, becomes highly susceptible when grown in the hot climate of Pusa in Bengal. Mr. Howard's reputation in applied botany is so well established that his views, particularly on possible administrative developments, merit serious consideration.

The programme of the Section of Anthropology indicates an active and serious interest in the varied problems of Indian ethnology and culture. If, however, those who took part in the proceedings had flung their nets wide, it is to be regretted that the burden of ethnological investigation still appears to rest on the shoulders of a few; and that the number of individual workers taking part was small. Further, while religious and sociological investigations were well represented, the study of material culture received little attention.

Among so many communications presenting features of interest it may appear invidious to select any for mention; but attention may be directed to Mr. L. A. Cammiade's account of the Kurnool bone caves in relation to the problem of prehistoric man in India ; Sarat Chandra Roy's description of the Asurs, a tribe of iron-smelters of Ranchi; Sarat Chandra Mitra's record of two recent cases of exorcism, one from Southern Bengal, for driving out the spirit of disease sent by Kali, a second from eastern Bengal, where treatment of a person possessed of a ghost by repeated immersion in water resulted fatally. The same author recorded two cases of propitiation by self-mutilation: a man cut off the tip of his tongue as an offering to Tapeswari at Cawnpur, while another individual in Kathiawara cut off his own head as an offering to Siva. An interesting rite to prevent hydrophobia, also recorded by Sarat Chandra Mitra, involves the turning by incantations, but otherwise unaided, of a saucer on which the patient stands. D. N. Majumdar presented further communications dealing with the customs of the Hos of Kolhan in continuation of those already published in several Indian periodicals.

In the Section of Zoology, under the presidency of Prof. H. R. Mehra of Benares, twenty-nine of the thirty-one papers presented are by Indian workers. They afford evidence of considerable scientific activity in the observation more especially of protozoa, parasitic worms, and Arthropoda.

Under the presidency of the Rev. W. E. Blatter, no less than 52 papers were communicated to the Section of Botany. These range over a wide field, many of them recording results of very general interest. The president is himself responsible for several ecological papers, mainly on the Indus delta; C. McCann also presented several papers on the grasses of the Bombay presidency; whilst several Indian workers supplied records of studies of special vegetation formations. The life-history of various Indian plants also received attention; a number of interesting communications in plant physiology are reported, and papers on parasitic fungi, on marine and fresh-water algæ, on cytology, teratology, heterophylly, and other biological features of interest in Indian plants, are included. In fact, the proceedings of the section suggest that the prosecution of research upon the interesting vegetation of India is actively pursued, and that Indian investigators are themselves taking a prominent share in the work.

The proceedings of the Section of Geology were noteworthy for the many papers devoted to Burma and its problems. A. S. Subbaiyer dealt with the production and reserves of petroleum and its stratigraphical distribution. He concludes that there may still be vast unexplored resources in the little-known Eocene oil-fields. In a third paper he discussed the genetic relationship between coal and oil, and suggests mapping the fixed carbon ratios in conjunction with structures as likely to lead to successful results,

NO. 2950, VOL. II 7 ] 
particularly along the Pakokku foot-hills. H. L. Chhibber contributed a valuable account of the extinct volcano Mt. Popa, one of the most conspicuous landmarks of Upper Burma. $\mathrm{He}$ also described the ferruginous concretions of the Irrawaddian Series, and the ancient slag-heaps and deserted furnaces found in the neighbourhood of Mt. Popa. Another paper by the same author described ferruginous bands of a rhythmic character occurring in the silicified tuffs of Kyankpadaung. H. L. Chhibber and L. D. Stamp collaborated in a paper dealing with the origin and constitution of the fossil wood which is such a conspicuous feature of the late Tertiary beds of Burma. The petrography of Green Island, near the mouth of the Salween, is described by L. D. Stamp, who directs attention to the extensive assimilation lit-par-lit injection, and development of banded gneisses that have taken place. K. K. Mathur et aliter discussed the mechanism of intrusion and the differentiation of the laccolith of Mt. Girner, the rocks of which were described many years ago by Dr. J. W. Evans. The Ranikot beds at Thal were shown by L. M. Davies to present a more complete series of the earliest Eocene horizons than has been discovered elsewhere. B. Sahni is engaged on a revision of the fossil plants in the collection of the Geological Survey, and presented a summary of his work on the conifers, ranging from the Lower Gondwana to the Cretaceous. Other papers dealt with cordierite, staurolite and mica, and various local faunas and strata; and J. Ribeiro describes the natural caves recently discovered in Bombay. The large number of contributors and the wide variety of subjects discussed testify to the healthy activity of geological research in India and Burma.

Nearly a hundred papers were presented to the Section of Mathematics and Physics. Seven of these deal with pure mathematics, five with hydrodynamical problems, and two with relativity and non-Euclidean space. The physical papers cover a wide range. Surface tension, efflux of gases, motion of projectiles, vibrating strings, flame temperatures, entropy, radiation, scattering of light, spectra, X-ray investigation of crystals, magnetism, electrolysis, photo-electricity and wireless signalling, were all discussed, while the wẹather, rainfall and floods of Bengal were not forgotten. Prof. M. N. Saha, as president of the section, read a valuable paper on the application of subatomic thermodynamics to astro-physics, portions of which were printed in NATURE of May 8 . The programme showed that India is keeping well abreast of recent developments in the mathematical and physical sciences.

\section{Co-operation in Oceanography.}

UNDER the title "L'Oceanographie dans la Vie International," Prof. Odon de Buen writes an interesting account of the various organisations which are materially assisting the co-operation of adjacent countries in oceanographical investigations (Scientia, February I, I926). The international movement is particularly active both in physical and biological oceanography, where the problems encountered by each country extend far beyond its own coasts, and the natural difficulties and expense of collecting data at frequent intervals over a wide area of the ocean necessitate such collaboration.

This necessity is increasing. Our present knowledge of the average conditions of the seas is built up from numerous painstaking observations made by a limited number of expeditions carried out from time to time. The fluctuations in the fisheries, of national importance to the countries concerned, centre interest more and more upon the fluctuations rather than upon the average condition in the physical and chemical conditions of the seas.

The Conseil Permanent International pour l'Exploration de la Mer now includes those countries bordering on the continental shelf from Norway to Portugal and
Spain. Its influence in furthering our knowledge of the oceans in general has been potent since its foundation in 1899 . Similar organisations deal with the publication of data and the co-ordination of investigations, both in the Mediterranean and also in the fertile area famed for its cod fishery north-east of North America.

These three co-ordinating organisations are represented in the Oceanographical Section of the Union International Geodesique et Geophysique by their respective presidents. It is of interest to hear that this section has commenced the difficult enterprise of publishing an annual Bibliographical Bulletin.

As any feral industry grows, whether it be hunting animals or fish, an accurate knowledge of the factors which control fluctuations in the population of the hunted animal becomes increasingly useful to the hunting nations. It is to gather this knowledge that the network of organisations has sprung up, fathered originally by the Scandinavian countries, to whom their fishing industry is an asset of relatively great importance. An interest in the sea is inherent in all seafaring nations, and concerted action has already been of great help to the progress of scientific oceanography.

\section{The Swiss National Park.}

PROF. CARL SCHROETER of Zürich delivered the fourth Hooker lecture at the Liınean Society on April I $_{5}$ on the Swiss National Park. The movement for Nature protection is very strong in Switzerland, and civil law permits even expropriation in the interest of natural and historical monuments. The formation of the League for the Protection of Nature (Naturschutzbund) has made the matter a national one; it has about 30,000 members, who pay an annual subscription of 2 francs, or 50 francs for life membership. The League has been instrumental in many ways, but the most effective measure is the creation of the Swiss National Park, which occupies about 54 square miles in the Lower Engadine. Here shooting, fishing, manuring, grazing, mowing and wood-cutting are entirely prohibited. No flower or twig may be gathered, no animal killed, no stone removed, and even fallen trees must remain undisturbed. There are no hotels, only simple Alpine shelter huts, and camping and the lighting of fires is not allowed. The aim is to exclude the effect of human interference so far as possible: scenery, plants and animals are absolutely protected.

The Park is controlled by five trustees nominated by the Government, which pays the rent (up to 30,000 francs per annum). The League pays the incidental expenses (e.g. there are four resident keepers) and for scientific research which is organised by the Swiss Society for the Advancement of Science.

The size of the Park and its physiography allow of Nature equilibrium. The mean elevation is high; the snow-line consequently reaches so much as 3000 metres; the tree-limit 2300 metres. It is well wooded with extensive forests of the erect mountain pine (Pinus

$$
\text { NO. 2950, VOL. II } 7 \text { ] }
$$

